\title{
Evaluation of Enteroneovesical Fistula by 64-Detector CT Enterography: A Case Report
}

\author{
Oktay Algin ${ }^{1, *}$; Melike Rusen Metin ${ }^{1}$; Mustafa Karaoglanoglu ${ }^{1}$ \\ ${ }^{1}$ Department of Radiology, Ataturk Training and Research Hospital, Ankara, Turkey \\ *Corresponding author: Oktay Algin, Department of Radiology, Ataturk Training and Research Hospital, Ankara, Turkey. Tel: +90-3122912525, E-mail: oktalgin@hotmail.com
}

Received: July 21, 2012; Revised: October 5, 2012; Accepted: October 27, 2012

\begin{abstract}
Enterovesical fistula is an abnormal communication between the bladder and the intestine. The accurate localization of leakage is importantforaccurate treatment planning. Some imaging techniques can not demonstrate the fistula; therefore, choosing the appropriate imaging technique is necessary. CT enterography (CTE) is a new technique for evaluation of the small bowel and the entire abdomen. CTE examination with multi-detector CT (MDCT) enables us to get excellent quality reformatted images with high spatial resolution. We report a patient with neobladder and enteroneovesical fistula. We showed the exact location of the fistula and its' association with the bowels and neobladder by CTE. The aim of this report is to show that CTE can be a new and effective modality in the detection of enteroneovesical fistulas and to discuss the efficacy of CTE in the detection and evaluation of enterovesical fistula referring to the literature. In conclusion, CTE may be a useful, sensitive, effective, and non-invasive technique for the evaluation of enteroneovesical fistula, leakage from the anastomose sides, and other extraintestinal complications such as urinary tract obstruction or abscess formation.
\end{abstract}

Keywords: Fistula; Bladder Cancer; Ileum; Urography

\section{Introduction}

Enterovesical fistula is an abnormal communication between the bladder and the intestine (1). It may occur as a result of postoperative complication of radical cystectomy and bladder substitution from the ileum, also called neobladder. The neobladder is connected to the ureters by a tube of ileal loops. Divided ileal loops are side-to-side or end-to-end anastomosed. Surgical incisions and the numerous anastomoses that are performed during these complex procedures can cause intestinal or vesical leakage postoperatively. Accurate localization of the leakage is important for accurate treatment planning.

Computed tomography (CT), cystoscopy, endoscopy, barium enema, and cystography are the techniques that are recently used for diagnosis of these fistulas (1). In some cases, these imaging techniques can not demonstrate the fistula because of their limitations. CT enterography (CTE) is a new technique for evaluation of small bowels, surrounding structures, and the entire abdomen (2-4). CTE examination with multi-detector CT (MDCT) enables us to get excellent quality reformatted images with high spatial resolution (3-5).

We report a patient with neobladder and enteroneovesical fistula. We showed the exact location of the fistula and its association with the bowels and neobladder by CTE. The leakage site was not demonstrated by conventional techniques so, CTE was applied. We demonstrated the location of the leakage with only one technique by CTE with no need of an invasive procedure. The aim of this case report is to show that CTE can be a new and effective modality in detecting enteroneovesical fistula and to discuss the efficacy of CTE in the detection and evaluation of enterovesical fistula referring to the literature. To the best of our knowledge, CTE usage in such cases has not been reported before in the literature so far. We think that this case report could be useful for early and correct diagnosis of similar cases.

\section{Case Presentation}

A 64-year-old man presented with feces coming from the transurethral catheter 5 days after radical cystectomy and neobladder operation. Urinary infection was detected in his clinical and laboratory observations. The fistula location could not be detected with abdominal ultrasonography (US), CT, cystoscopy, antegrade pyelography, barium enema and cystography (Figure 1). Clinicians suspected postcystectomic enteroneovesical fistula, so CTE was performed.

$1250 \mathrm{~mL}$ of oral contrast-material solution, which was composed of $500 \mathrm{~mL}$ water, $200 \mathrm{~mL}$ lactulose (667 mg/ $\mathrm{mL}$, Osmolac, Biofarma, Turkey), and $450 \mathrm{~mL}$ dilutemixed barium sulfate suspension especially designed for CT (E-Z-Cat, Opakim, Turkey), was ingested orally over 60 minutes at a steady rate. After administration of oral con-

Copyright ( 2015 , Tehran University of Medical Sciences and Iranian Society of Radiology. This is an open-access article distributed under the terms of the Creative Commons Attribution-NonCommercial 4.0 International License (http://creativecommons.org/licenses/by-nc/4.0/) which permits copy and redistribute the material just in noncommercial usages, provided the original work is properly cited. 
trast agent, CTE with $2 \mathrm{~mm}$ slice thickness was performed with a 64-detector MDCT machine (Aquilion 64, Toshiba, Tokyo, Japan). After CTE examination, sagittal and coronal reformatted images (slice thickness: $1 \mathrm{~mm}$ ) were obtained by routinely available workstation inside the MDCT machine. Intravenous and rectal contrast agents were not given to the patient. Ileoneovesical fistula (from the anastomose side) was determined on CTE images (Figure 2). Therefore, follow-up with transurethral catheter was recommended. If necessary, operation was planned.

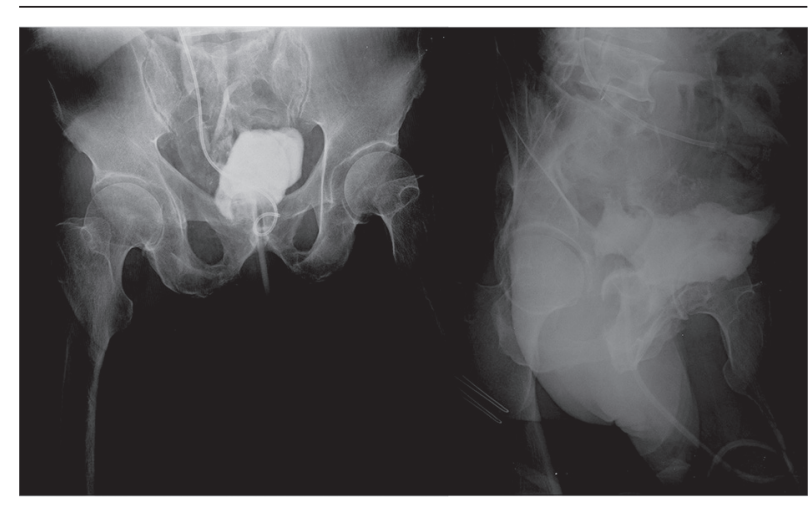

Figure 1. A 64-year-old man who has feces exiting from the transurethral catheter after radical cystectomy and neobladder operation. The cystography images do not show evidence of enteroneovesical leakage or fistula.

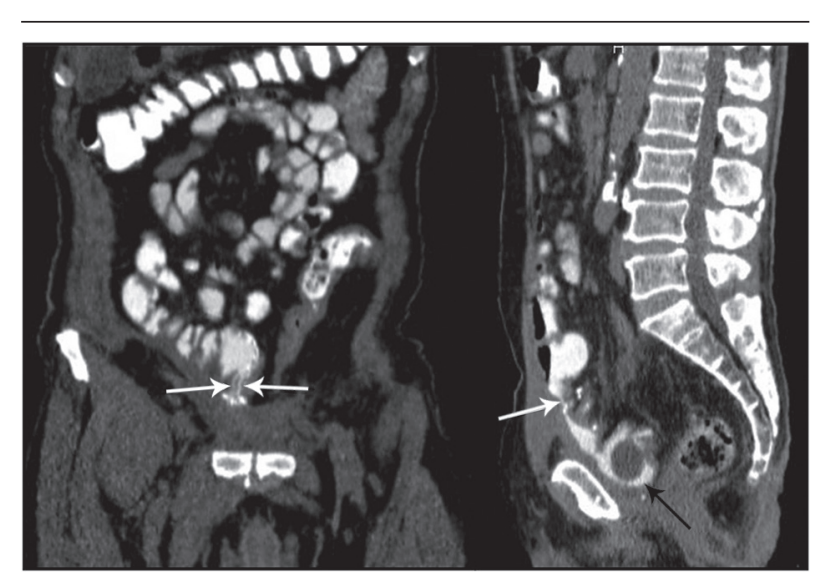

Figure 2. Coronal (left) and sagittal (right) CTE images. Ileoneovesical fistula tracts are clearly visible on the images (white arrows). The neobladder and foley catheter balloon are also seen (black arrow).

\section{Discussion}

Enteroneovesical fistula is a rare condition that can be difficult to diagnose (1). The most common causes of enterovesical fistulas are Crohn disease, enteritis, ulcerative colitis, trauma, postoperative-postradiotheraphy complications, penetrating injuries, bladder carcinomas, pelvic inflammatory disease, foreign bodies, and abscesses $(6,7)$. In addition, they may occur as a postoperative complication of radical cystectomy and neobladder substitution procedure. Fecaluria is the most common clinical presentation in these cases. The other common findings are pneumaturia and recurrent urinary infections $(6,7)$. However, classical symptoms are only evident in 50\% of patients with confirmed fistulae (1).

CT, cystoscopy, endoscopy, barium enema, and cystography are mainly used for diagnosis of enterovesical fistulas (1). Neocystogram examination of the neobladder (after administration of a diluted contrast agent solution via transurethral catheter) is the most frequent method used for the diagnosis of enteroneovesical fistula $(6,7)$. However, it is not always possible to detect fistula localization definitely with neocystography. Another disadvantage of neocystography is that the diluted contrast agent solution given into the bladder with high pressure and in large amounts can result in a new leakage site iatrogenically.

Some CT criteria are used for diagnosis of enterovesical fistulas such as presence of air within the bladder, focal bladder-bowel wall thickening, and presence of an associated soft-tissue mass $(6,7)$. However, the percentages of success in demonstrating the fistulas are not as high as it is expected $(6,7)$. As a result, another new technique is necessary to demonstrate enterovesical fistulas, their causes, and the communication site. The fact that in our case, the fistula and its localization were not detected by other techniques and were only detected by CTE, supports this idea.

CTE has become a valuable technique in detecting small bowel diseases such as obscure gastrointestinal bleeding, suspected small-bowel tumor and especially inflammatory bowel diseases (3-5). CTE is a well-tolerated imaging technique that unlike CT enteroclysis, does not need nasoenteric intubation $(8,9)$. The images taken following the ingestion of large amounts of oral contrast material enables us to detect the small bowel lumen and wall more successfully (2-4). Small bowel distension also makes contrast agent leakage from the fistula more prominent. As a result, leakages that cannot be detected by routine CT can be detected by CTE. CTE examination with 64 MDCT enables us to get isotropic voxels and excellent quality reformatted images with high spatial resolution that is more easily diagnosed while evaluating the operation site and neobladder (2-5).

CTE may be a useful, sensitive, effective, and non-invasive technique for the evaluation of enteroneovesical fistulas, leakage from the anastomose sides in postoperative cases, and other extraintestinal complications such as urinary tract obstruction or abscess formation.

\section{References}

1. Kavanagh D, Neary P, Dodd JD, Sheahan KM, O'Donoghue D, Hyland JM. Diagnosis and treatment of enterovesical fistulae. Colorectal Dis. 2005;7(3):286-91.

2. Hong SS, Kim AY, Kwon SB, Kim PN, Lee MG, Ha HK. Three-dimensional CT enterography using oral gastrografin in patients with small bowel obstruction: comparison with axial CT images or fluoroscopic findings. Abdom Imaging. 2010;35(5):556-62.

3. Huprich JE, Fletcher JG, Alexander JA, Fidler JL, Burton SS, McCullough $\mathrm{CH}$. Obscure gastrointestinal bleeding: evaluation 
with 64-section multiphase CT enterography-initial experience. Radiology. 2008;246(2):562-71.

4. Paulsen SR, Huprich JE, Fletcher JG, Booya F, Young BM, Fidler JL, et al. CT enterography as a diagnostic tool in evaluating small bowel disorders: review of clinical experience with over 700 cases. Radiographics. 2006;26(3):641-57.

5. Macari M, Megibow AJ, Balthazar EJ. A pattern approach to the abnormal small bowel: observations at MDCT and CT enterography. AJR Am J Roentgenol. 2007;188(5):1344-55.

6. Ubirajara Barroso J, da Silva EA, Alvim Barroso V, Gomes de Oliveira J, Edson Pontes J. [The diagnosis and treatment of a postcystec- tomy enteroneovesical fistula]. Actas Urol Esp.1999;23(7):573-8.

7. Goldman SM, Fishman EK, Gatewood OM, Jones B, Siegelman SS. CT in the diagnosis of enterovesical fistulae. AJR Am J Roentgenol. 1985;144(6):1229-33.

8. Arslan H, Etlik O, Kayan M, Harman M, Tuncer Y, Temizoz O. Peroral CT enterography with lactulose solution: preliminary observations. AJR Am J Roentgenol. 2005;185(5):1173-9.

9. Algin O, Evrimler S, Ozmen E, Metin M, Ersoy O, Karaoglanoglu M. Desmoid Tumor Associated With Familial Adenomatous Polyposis: Evaluation With 64-Detector CT Enterography. Iran J Radiol. 2012;9(1):32-6. 